\title{
Genetic Analysis of Developmentally Regulated Resistance to Downy Mildew (Hyaloperonospora parasitica) in Arabidopsis thaliana
}

\author{
John M. McDowell, ${ }^{1}$ Scott G. Williams, ${ }^{2}$ Nicholas T. Funderburg, ${ }^{1}$ Thomas Eulgem, ${ }^{2}$ and \\ Jeffery L. Dangl ${ }^{2,3}$ \\ ${ }^{1}$ Department of Plant Pathology, Physiology, and Weed Science, and Fralin Biotechnology Center, Virginia Polytechnic \\ Institute and State University, Blacksburg, Virginia 24061-0346, U.S.A.; ${ }^{2}$ Department of Biology, ${ }^{3}$ Department \\ of Microbiology and Immunology, Curriculum in Genetics, and Carolina Center for Genome Sciences, University \\ of North Carolina, Chapel Hill, North Carolina 27599 U.S.A.
}

Submitted 5 May 2005. Accepted 4 August 2005.

\begin{abstract}
Although developmentally regulated disease resistance has been observed in a variety of plant-pathogen interactions, the molecular basis of this phenomenon is not well understood. Arabidopsis thaliana ecotype Columbia-0 (Col-0) expresses a developmentally regulated resistance to Hyaloperonospora parasitica isolate Emco5. Col-0 seedlings support profuse mycelial growth and asexual spore formation in the cotyledons. In contrast, Emco5 growth and reproducetion is dramatically (but not completely) restricted in the first set of true leaves. Subsequent leaves exhibit progresssively increased resistance. This adult resistance is strongly suppressed by expression of the salicylic acid-degrading transgene $N a h G$ and by loss-of-function mutations in the defense-response regulators $P A D 4, N D R 1, R A R 1, P B S 3$, and $N P R 1$. In contrast to Col-0, the Wassilewskija-0 (Ws-0) ecotype supports profuse growth of Emco5 at all stages of development. Gene-dosage experiments and segregation patterns indicate that adult susceptibility in Ws-0 is incomepletely dominant to adult resistance in Col-0. Genetic mapping in a Col $\times$ Ws F2 population revealed a major locus on the bottom arm of chromosome 5, which we named $R P P 31$. Analysis of T-DNA insertion lines indicated that the Columbia allele of $R P P 8$, though tightly linked to $R P P 31$, is not necessary for adult resistance.
\end{abstract}

Additional keywords: adult plant resistance, age-related resistance, gene-for-gene resistance, haploinsufficiency, oomycete.

Plants have evolved multiple lines of defense against pathogens and pests. These include preformed barriers as well as inducible defenses that are activated only when pathogens are perceived by the plant (Hammond-Kosack and Jones 1996; Osbourn 1996). Several distinct inducible defense mechanisms have been posited on the basis of genetic and molecular studies. The best-studied defense mechanism is "gene-for-gene" resistance, which is based on perception of pathogen aviru-

Corresponding author: John M. McDowell; E-mail: johnmcd@vt.edu; Telephone: 540-231-2388; Fax: 540-231-7126.

Current address of T. Eulgem: Center for Plant Cell Biology \& Department of Botany and Plant Sciences, University of California, Riverside, CA, 92521, U.S.A. lence $(a v r)$ gene products by corresponding resistance $(\mathrm{R})$ proteins in the plant (Dangl and Jones 2001; Flor 1955). In some cases, $a v r$ genes have been shown to encode virulence factors (effectors) that function inside plant cells to interdict plant regulatory pathways and create a more favorable environment for the pathogen (Chang et al. 2004; van't Slot and Knogge 2002). $R$ genes encode receptors that might either physically interact with the cognate effector, detect the molecular consequences of effector action, or both (Dangl and Jones 2001; Van der Biezen and Jones 1998). This molecular recognition activates a complex signaling network that controls activation of defense responses in the vicinity of infection sites (HammondKosack and Parker 2003; McDowell and Dangl 2000). These localized defenses include programmed cell death (the hypersensitive response), physical reinforcements, and biosynthesis of antimicrobial compounds (e.g., phytoalexins and pathogenesis-related proteins) (Hammond-Kosack and Jones 1996). Genetic studies in Arabidopsis have defined a distinct layer of "basal" resistance that acts in the absence of gene-for-gene recognition to limit the growth of virulent pathogens (Glazebrook et al. 1997). Mutant analyses and microarray studies have revealed extensive regulatory overlap between basal resistance and $R$ gene-dependent resistance, suggesting that $R$ genes function to activate a faster and more potent elaboration of basal defenses (Katagiri 2004; Tao et al. 2003). Finally, two types of induced, systemic defense responses have been shown to provide resistance against a relatively broad spectrum of otherwise virulent pathogens: systemic acquired resistance (SAR), which can be induced throughout the plant after a localized pathogen attack and requires the phenolic signal salicylic acid (SA) (Durrant and Dong 2004) and induced systemic resistance (ISR), which is induced by rhizosphere bacteria through a mechanism that uses components of the ethylene and jasmonic acid (JA) pathways (Pieterse et al. 2003).

In some plant-pathogen interactions, defenses are effective only at specific developmental stages. This phenomenon has been referred to as developmental resistance, adult plant resistance, mature plant resistance, ontogenic resistance, or age-related resistance. Examples of developmental resistance to viruses, bacteria, fungi, oomycetes, and insects have been documented in many crops (Panter and Jones 2002). Several sources of developmental resistance have been defined genetically and deployed effectively in the field through classical breeding. For example, 
genes for adult resistance to powdery mildew (Griffey et al. 1993; Liu et al. 2001), stem rust (Sunderwirth and Roelfs 1980), and leaf rust (Kolmer 1996) have provided relatively durable disease control in wheat. It has been suggested that developmental resistances may be more stable over evolutionary time because susceptible tissue provides a refugium for the pathogen, thereby attenuating selection for resistance-breaking mutations (Parniske et al. 1997). However, developmental resistance can also provide windows of opportunity for pathogens to cause significant damage to susceptible tissue (Brophy and Laing 1992). A better understanding of why defenses are inactive at certain developmental stages might open new avenues for engineering developmentally uniform resistance. From a more fundamental perspective, genetic analysis of developmental resistance provides an opportunity to explore cross talk between molecular networks that regulate development and immunity. However, developmental resistance mechanisms have not been extensively studied at the molecular level (Panter and Jones 2002).

Disease resistance mechanisms in Arabidopsis have been defined primarily through the use of Pseudomonas syringae (Quirino and Bent 2003) and the oomycete Hyaloperonospora parasitica (Holub and Beynon 1996; Slusarenko and Schlaich 2003) as model pathogens. H. parasitica causes downy mildew disease on wild populations of Arabidopsis and is a destructive pathogen of cultivated Brassicas (Clark and Spencer-Phillips 2000). Extensive genetic diversity has been documented in the interaction between Arabidopsis and H. parasitica, indicative of rapid and dynamic co-evolution between the host and the parasite (Holub and Beynon 1996; Slusarenko and Schlaich 2003). This intraspecific polymorphism has proven useful for molecular genetic analysis of resistance, because it has permitted genetic definition and molecular cloning of $R P P$ (isolatespecific resistance to Hyaloperonospora parasitica) genes. To date, 30 distinct $R P P$ genes have been genetically defined (Holub 1997; Holub and Beynon 1996; Holub et al. 1994; Holub 2001) and 11 have been molecularly cloned by mapbased methods (Slusarenko and Schlaich 2003; Tor et al. 2004). Every RPP gene cloned to date (with one exception [Tor et al. 2004]) belongs to the nucleotide binding site-leucinerich repeat (NBS-LRR) resistance gene superfamily (Jones and Jones 1996; Tameling et al. 2002).

Age-related resistance in Arabidopsis against two pathovars of $P$. syringae was recently defined and was shown to be genetically distinct from other forms of resistance (Kus et al. 2002). In this report, we describe a developmentally regulated resistance in Arabidopsis to the Emco5 isolate of H. parasitica. This resistance is incomplete in the first two true leaves and becomes more efficient as development proceeds. This resistance is activated specifically in the Col-0 ecotype and is not functional in Ws- 0 . A previous paper noted that this resistance was correlated with an oxidative burst and programmed cell death (Torres et al. 2002). In this report, we characterized the resistance in detail, to address the following questions: Is this resistance race-specific? Does the developmentally regulated disease resistance require genetic components of previously documented disease resistance mechanisms? Is developmentally regulated resistance in Col-0 genetically dominant to susceptibility in Ws- 0 , and how many loci relevant for expression of this resistance can be defined in a segregating Col- $0 \times \mathrm{Ws}-0$ population?

\section{RESULTS}

\section{Developmentally regulated resistance}

to $H$. parasitica Emco5 is activated

in true leaves of Arabidopsis Col-0 but not Ws-0.

As previously documented (Aarts et al. 1998; Holub et al. 1993; McDowell et al. 1998, 2000) and shown in Figure 1, seedlings of Arabidopsis ecotype Columbia (Col-0) are highly susceptible to the Emco5 isolate of $H$. parasitica. Visual examination (Fig. 1A) and trypan blue staining (Fig. 1B) of Col-0 seedlings 7 days after inoculation (dai) revealed abundant asexual fruiting bodies (sporangiophores) and sexual spores (oospores) as well as an extensive mycelium of intracellular hyphae. Wassilewskija (Ws-0) seedlings are also susceptible to Emco5 (Figs. 1 and 2A) (McDowell et al. 2000). Landsberg erecta (Ler) seedlings exhibited complete resistance to Emco5, due to race-specific recognition provided by the RPP8-Ler gene (Fig. 1A) (Holub et al. 1993; McDowell et al. 1998).

In contrast to susceptible Col-0 cotyledons, true leaves of Col-0 exhibited significant resistance to Emco5. This was first apparent in 14-day-old seedlings, where the first two true leaves

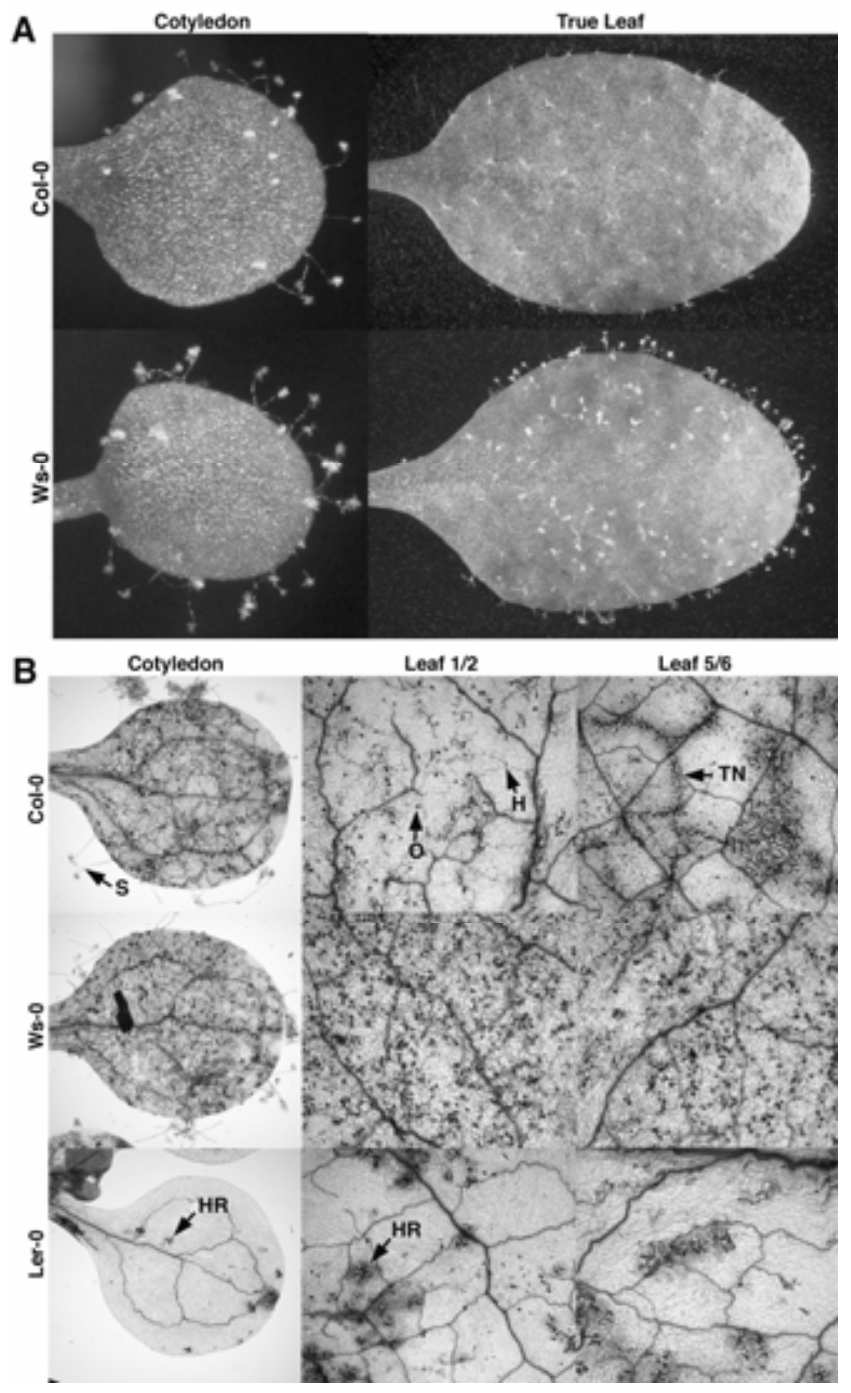

Fig. 1. Vegetative growth and asexual reproduction of Hyaloperonospora parasitica Emco5 during development of the Col-0 and Ws-0 ecotypes of Arabidopsis. All images were captured at 7 days after inoculation. The images depict phenotypes observed in three to eight independent experiments, each with at least five plants. A, Asexual sporulation of Emco5 on a representative cotyledon from seedlings inoculated at 7 days after germination and a representative true leaf from plants inoculated at five weeks after germination. B, Cotyledons or representatives from the first (leaf 1/2) or third pair (leaf 5/6) of true leaves, from Columbia (Col-0), Wassilewskija (Ws-0), or Landsberg erecta (Ler-0) ecotypes, stained with trypan blue. True leaves are numbered according the order in which they emerged (Telfer et al., 1997). Trypan-blue staining highlighted asexual sporangiophores $(\mathrm{S})$, vegetative hyphae $(\mathrm{H})$, sexual oospores $(\mathrm{O})$, hypersensitive response (HR) sites, and trailing necrosis (TN) that results from a delayed HR after limited hyphal growth. 
A

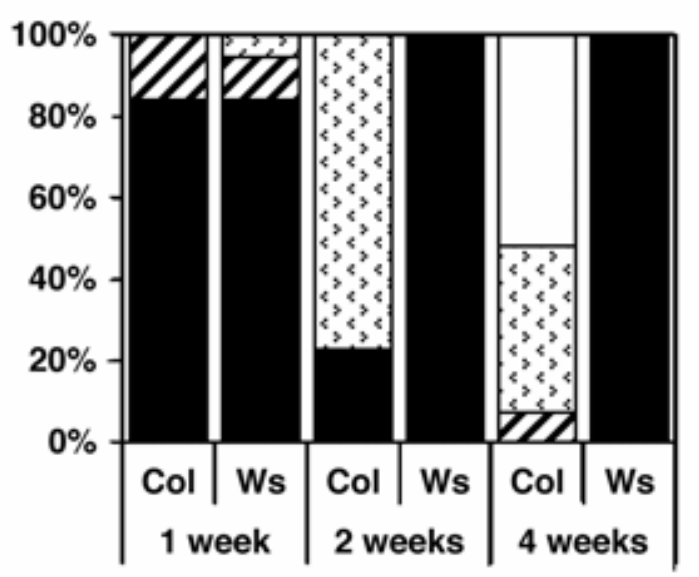

B

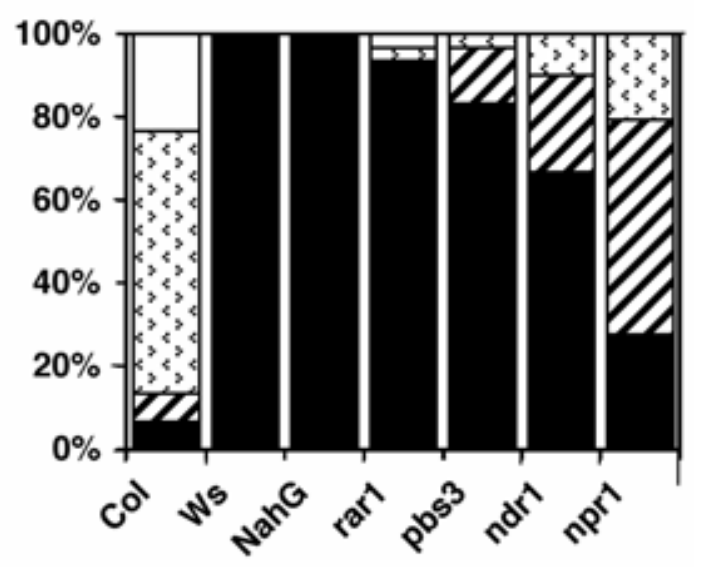

C

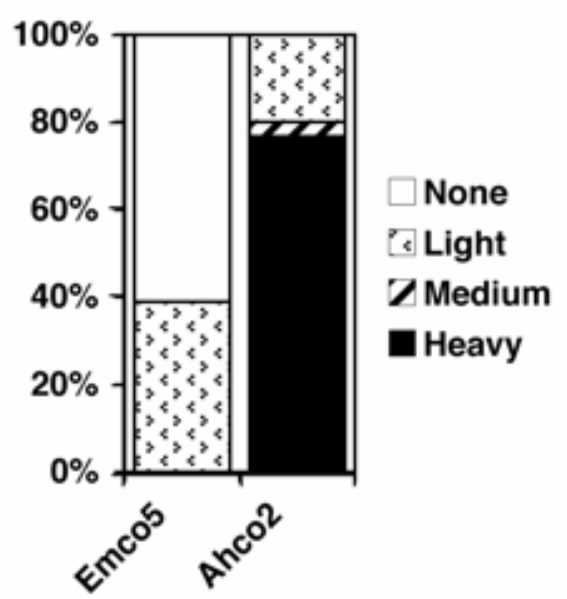

Fig. 2. Disease scores in seedlings and adult plants, based on sporangiophore production. Bar graphs depict percentages of cotyledons or true leaves that were scored as none (no sporangiophores per cotyledon or leaf), light (1 to 10 sporangiophores), medium (11 to 19), or heavy $(>19)$, at 7 days after inoculation. Each genotype was tested in at least three independent experiments with similar results. Representative experiments are shown. A, Col-0 or Ws-0 plants, inoculated with Emco5 at 1,2 , or 4 weeks after germination. The 1 -week percentages were calculated from 20 cotyledons scored from 10 plants. The 2- and 4-week percentages were calculated from 19 to 40 true leaves scored from 4 to 6 individual plants. B, 3-week-old Col-0, Ws-0, Col::NahG, rarl-20, pbs3, $n d r 1-1$, or $n p r 1-1$ plants inoculated with Emco5. The pad4-1 mutant also displayed a phenotype of strong susceptibility (data not shown). Percentages were calculated from 29 to 30 leaves from five plants of each genotype. C, 4-week-old Col-0 or Ws-0 plants inoculated with Emco5 or Ahco2. Percentages were calculated, respectively, from 30 or 36 leaves taken from five or six plants. supported markedly reduced numbers of sporangiophores, as compared with cotyledons (Fig. 2A). This phenotype is even more pronounced in true leaves of three- and four-week-old plants (Fig. 2A and B). Trailing necrosis, indicative of a delayed hypersensitive response, was observed to a limited extent in the first two true leaves and was much more extensive in leaves that subsequently emerged (Fig. 1B). Conversely, we typically observed that the first two true leaves supported significantly higher levels of hyphal growth, oospores, and sporangiophores than did subsequent leaves (Fig. 1B). Older plants (i.e., five to seven weeks after germination) often displayed complete resistance in all leaves (Fig. 1A). Control Col-0 plants expressing an RPP8-Ler transgene were completely resistant to Emco5 at all developmental stages (Fig. 3).

In contrast to Col-0, Ws-0 was highly susceptible to Emco5 throughout development. True leaves of Ws-0 supported very high levels of mycelial growth, oospores, and sporangiophores, regardless of developmental stage (Figs. 1 and 2A and B). Thus, the developmental resistance to Emco5 is specific to the Columbia ecotype and is not a general Arabidopsis response. In addition, Ws::NahG transgenic plants (Delaney et al. 1994) supported even higher levels of Emco5 sporulation than did wild-type Ws-0 (data not shown). This suggests that Ws-0, although susceptible, expresses a basal defense mechanism that limits the growth of virulent Emco5. Basal defense against $H$. parasitica has been documented previously (Parker et al.

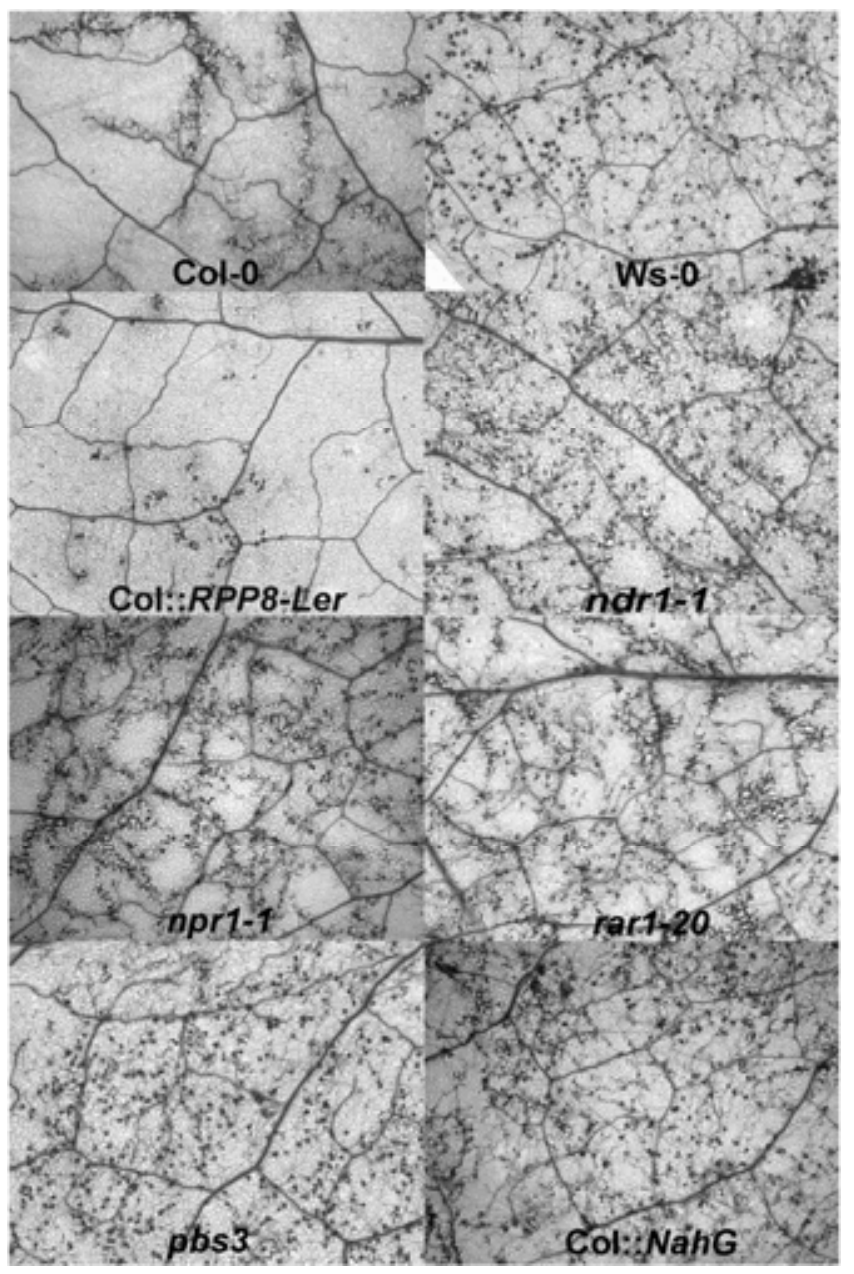

Fig. 3. Adult-resistance phenotypes of transgenic lines or mutants in the Columbia background inoculated with Emco5. True leaves were inoculated at 3 weeks after germination and were stained with trypan blue at 7 days after inoculation. The images depict phenotypes observed in two independent experiments. 
1996). As in Col-0, the RPP8-Ler transgene in adult Ws-0 plants provided strong resistance to Emco5 (data not shown), demonstrating that Ws- 0 contains all components necessary for resistance to Emco5 except for an appropriate $R$ gene.

\section{Adult resistance in Col-0 is race-specific and is suppressed by defense signal transduction mutants.}

The incompatibility between Emco5 and Col-0 adult leaves could reflect a race nonspecific adult resistance against many $H$. parasitica isolates, as previously documented for some adult resistances (Panter and Jones 2002). However, we and others have previously observed that adult Col-0 plants are susceptible to $H$. parasitica isolate Noco2, suggesting that the developmental resistance in Col-0 against Emco5 is race-specific (J. M. McDowell, unpublished data) (Bowling et al. 1994; Clarke et al. 1998; Korves and Bergelson 2003). To generalize this further, we inoculated 4-week-old Col-0 plants with the Ahco 2 isolate, previously shown to be virulent on Col-0 seedlings (Holub and Beynon 1996; Holub et al. 1993). We observed that true leaves of Col- 0 are highly susceptible to Ahco2 (Fig. 2C). Thus, adult resistance in Col-0 against Emco5 does not reflect a general resistance against all $\mathrm{H}$. parasitica isolates.

The trailing necrosis/hypersensitive response in true leaves (Fig. 1B) along with hydrogen peroxide production at the infection site (Torres et al. 2002) indicates that the incompatibility of adult Col-0 and Emco5 results from an active defense response in the host. To substantiate this further and to determine whether the resistance in Col-0 true leaves is genetically distinct from previously documented resistance mechanisms in Arabidopsis, we challenged three-week-old, isogenic Col lines containing mutations or transgenes known to suppress disease resistance responses. These included a $\mathrm{Col}:$ NahG transgenic line (Delaney et al. 1994) and loss-of-function mutants nprl-1 and pad4-1 (Cao et al. 1997; Jirage et al. 1999; McDowell et al. 2000). Each of these lines is deficient in SA-mediated signaling, thereby impairing basal resistance, SAR, and certain $R$ genes. We also challenged the $n d r 1-1$ mutant, in which certain $R$ genes as well as SA-mediated responses are suppressed (Century et al. 1997; Coppinger et al. 2004; McDowell et al. 2000; Shapiro and Zhang 2001), the rarl-20 mutant that exhibits reduced $\mathrm{R}$ protein stability (Bieri et al. 2004; Shirasu and Schulze-Lefert 2003; Tornero et al. 2002), and the pbs3 mutant, in which certain $R$ genes are suppressed through an unknown mechanism (Warren et al. 1999). Adult resistance to Emco5 was significantly suppressed in each of these backgrounds. The strongest suppression was observed in $N a h G$ transgenic plants, in which Emco5 mycelial growth and sporulation matched or slightly exceeded Ws controls. In contrast, the nprl-1 mutation only partially suppressed resistance and displayed limited trailing necrosis indicative of a delayed resistance response. The pad4-1, rarl-20, pbs3, and ndrl-1 phenotypes were intermediate to those of $N a h G$ and $n p r l-1$. The jasmonate-response mutant jarl (Staswick et al. 2005) displayed no alteration of adult resistance (data not shown). Taken together, these results demonstrate that the adult resistance in Col-0 requires a variety of regulatory components previously associated with inducible defenses.

\section{Genetic analysis of adult resistance.}

Resistance to pathogens is often genetically dominant to susceptibility, particularly when conferred by an $R$ gene (Crute and Pink 1996). To determine whether adult resistance in Col0 is genetically dominant to susceptibility in Ws- 0 , we examined resistance to Emco5 in F1 and F2 progeny from crosses between Col and Ws-0 (Table 1, Fig. 4). None of the Ws-0 $\times$ Col-0 F1 progeny displayed a Col-like resistance phenotype. The majority of F1s were just as susceptible as parental Ws to

Table 1. Segregation of adult resistance to Hyaloperonospora parasitica Emco5

\begin{tabular}{|c|c|c|c|c|c|c|}
\hline \multirow[b]{2}{*}{$\operatorname{Cross}^{\mathrm{a}}$} & \multicolumn{3}{|c|}{ F1 } & \multicolumn{2}{|c|}{ F2 } & \multirow[b]{2}{*}{$\chi^{2 \mathrm{e}}$} \\
\hline & $\operatorname{Res}^{b}$ & Sus & Int & $\operatorname{Res}^{c}$ & Sus $^{d}$ & \\
\hline rpm1-3 (Col-5) $\times$ Ws -0 & 0 & 8 & 2 & 89 & 30 & $1.09(P>0.3)$ \\
\hline Col- $0 \times$ Ws -0 & 0 & 6 & 3 & & & \\
\hline Ws $-0 \times$ Col- 0 & 0 & 2 & 4 & & & \\
\hline Ws $-0 \times$ CS3432 & 1 & 0 & 5 & & & \\
\hline $\mathrm{CS} 3432 \times \mathrm{Ws}-0$ & 0 & 0 & 6 & & & \\
\hline $\mathrm{CS} 3151 \times \mathrm{Ws}-0$ & 0 & 0 & 4 & & & \\
\hline
\end{tabular}

${ }^{a}$ Data were pooled from four experiments. The pollen recipient is listed first.

${ }^{\mathrm{b}}$ Res = resistant phenotype, resembling Col-0 parent; Sus = susceptible phenotype, resembling Ws-0 parent; Int = intermediate phenotype.

${ }^{\mathrm{c}}$ Each resistant F2 plant was inoculated twice with Emco5 to confirm that the resistant phenotype was not due to a low dose of inoculum.

${ }^{\mathrm{d}}$ Plants displaying an intermediate phenotype were scored as susceptible.

${ }^{\mathrm{e}} \chi^{2}$ and probability $(P)$ values are given for the expected $1: 3$ resistant/susceptible ratio.

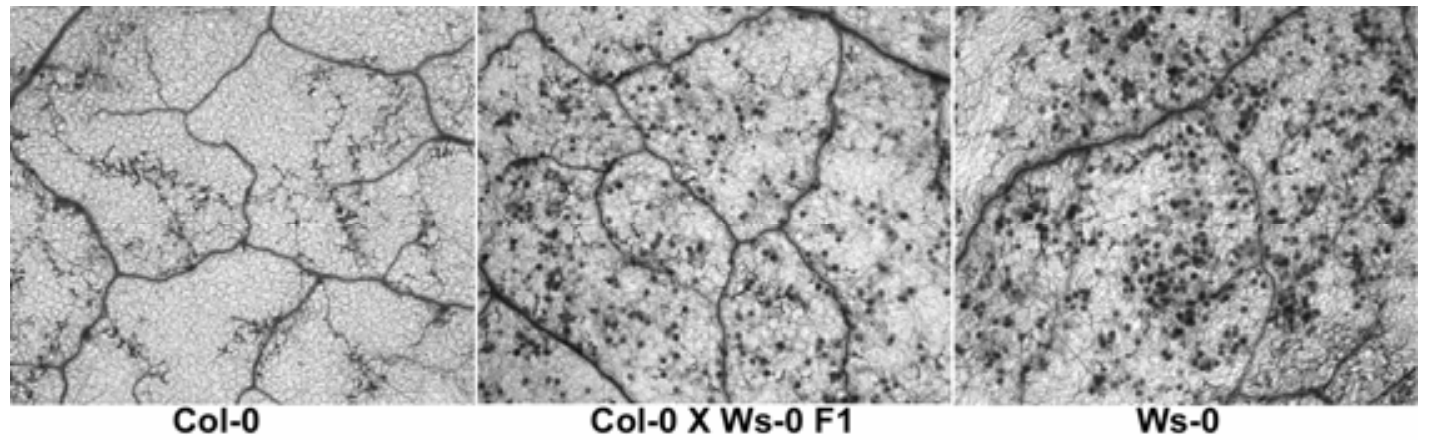

Fig. 4. Adult-resistance phenotype in F1 progeny from a cross of Ws- 0 to Col-0. Representative leaves from Col-0, Ws- 0 , and a Ws- $0 \times$ Col-0 F1 progeny, inoculated at 3 weeks after germination and stained with trypan blue at 7 days after inoculation. The images depict phenotypes observed in four independent experiments 
Emco5, while a minority displayed intermediate levels of susceptibility. These phenotypes indicate that susceptibility is incompletely dominant to resistance. F2 segregation ratios were consistent with this interpretation. Only $24 \%$ of F2 progeny displayed Col-like adult resistance, while the remaining $76 \%$ displayed full (Ws-like) or intermediate susceptibility to Emco5. This segregation ratio of 1:3 resistant/susceptible indicates that the phenotypic difference between $\mathrm{Col}$ and Ws-0 is due to a single, recessive gene.

The recessivity of resistance in the Col- $0 \times$ Ws- 0 hybrid could be a gene-dosage effect, in which one copy of a Col-0 allele is insufficient to activate adult resistance (termed haploinsufficiency). Alternatively, Ws-0 might express a susceptibility allele that is truly dominant, perhaps through a negative effect on a Col-0 resistance allele. To better understand the genetic basis of susceptibility in the Col- $0 \times$ Ws- 0 hybrid, we conducted a gene-dosage experiment in which we examined the adult resistance phenotype of triploid plants containing two copies of each Col chromosome and one copy of each Ws-0 chromosome (genotype $\mathrm{Col} / \mathrm{Col} / \mathrm{Ws}-0$ ). Triploid plants were constructed by crossing diploid Ws- 0 with two tetraploid derivatives of Col (CS3151, CS3432) (Greenberg 2000). If resistance is recessive because of Col-0 haploinsufficiency in diploid Col- $0 \times$ Ws-0 F1s, then triploid plants should display Collike adult resistance. We did not observe this phenotype; almost every F1 from crosses to CS3151 or CS3432 displayed clearly enhanced sporulation compared to Col-0, CS3151, and CS3432 parents (Table 1). However, the triploid F1s consistently supported less sporulation than either Ws-0 parents or diploid F1 progeny from wild-type Col- $0 \times$ Ws- 0 crosses. These phenotypes indicate that the Ws- 0 susceptibility phenotype is dominant (albeit incompletely) to resistance in Col-0.

We genetically mapped the adult resistance phenotype in Col-0 $\times$ Ws-0 F2s, using polymerase chain reaction (PCR)based markers (cleaved amplified polymorphic sequences [CAPS] or simple sequence length polymorphisms [SSLP]) on each of the 10 Arabidopsis chromosome arms (Table 2). Because adult resistance is recessive, we performed the mapping with a set of $89 \mathrm{~F} 2 \mathrm{~s}$ that displayed a clear adult resistance phenotype and were presumably homozygous for one or more recessive Col-0 resistance alleles. We observed strong linkage of the resistance phenotype to the bottom arm of chromosome 5 , in a region between the $s p l 2$ and $n g a 129$ molecular markers (Table 2). We hypothesize that a major gene for adult resistance in Col-0 resides in this interval. We named this gene $R P P 31$, following the previously established convention for naming Arabidopsis genes that provide resistance to Hyaloperonospora parasitica. We also observed weak linkage to the bottom of chromosome 2, suggesting the existence of a weak modifier of the resistance phenotype (Table 2).
No $R P P$ gene has been previously mapped in the Columbia ecotype to the interval between $s p l 2$ and ngal29. However, the RPP8 resistance gene from the Landsberg erecta ecotype (RPP8-Ler) is located approximately $1 \mathrm{cM}$ south of $s p l 2$, based on mapping in the Dean-Lister Col $\times$ Ler recombinant inbred population (McDowell et al. 1998). RPP8-Ler was previously defined by its ability to provide resistance to Emco5 when expressed as a transgene in Emco5-susceptible Col-0 or Ws-0 seedlings (McDowell et al. 1998, 2000). The Col-0 allele of $R P P 8$ is transcribed, and encodes an NBS-LRR protein with $92 \%$ amino acid identity to RPP8-Ler. Although RPP8-Col does not provide resistance to Emco5 in seedlings, it could potentially function in adult resistance. To test this possibility, we challenged two lines from the Salk T-DNA mutant collection that contained independent insertions in RPP8-Col (SALK_046059, SALK_001957) (Alonso et al. 2003). The SALK_46059 insertion maps to codon 13 in exon 1, just downstream of the translation initiation site. The SALK_001957 insertion maps to codon 647 in exon 3, within the fifth of 14 LRR. These insertions presumably result in null alleles. We used PCR to confirm that each line contains T-DNA at the documented location. We inoculated 38 and 22 individuals, respectively, from T3 populations segregating for the SALK_046059 and SALK_001957 insertions. Each of these individuals displayed a clear adult resistance phenotype, indistinguishable from Col-0 controls (data not shown). Subsequent PCR tests of 12 Emco5-challenged plants from each population confirmed that the T-DNA insertions in RPP8-Col were segregating at approximately the expected genotypic ratio of $1: 2: 1$ wild-type/hemizygote/homozygous knockout, in both populations. The absence of Emco5-susceptible adult plants in these populations indicated that $R P P 8-C o l$ is unnecessary for adult resistance to Emco5.

\section{DISCUSSION}

Although developmentally regulated disease resistance has not been well-studied at the molecular level, several experimentally tractable pathosystems have been recently developed. Initial studies with these systems indicate that many distinct mechanisms underlie the phenomenon of developmental resistance (Panter and Jones 2002). In several cases, resistance has been correlated with the transition to reproductive growth. For example, developmental resistance in Arabidopsis to P. syringae (referred to by the authors as age-related resistance [ARR]) has been correlated with the transition to flowering and is also activated by abiotic stress (Cameron and Zaton 2005; Kus et al. 2002). This resistance requires SA accumulation in the intercellular space but is not compromised by the npr1-1, pad3-1, or eds7-1 mutations. These results indicate

Table 2. Genetic mapping of the adult-resistance phenotype

\begin{tabular}{|c|c|c|c|c|c|c|}
\hline Marker $^{a}$ & Chromosome & $\mathbf{c M}^{\mathbf{b}}$ & Recombinant chromosomes & Total chromosomes & Recombination frequency $(\%)$ & $\chi^{2 \mathrm{c}}$ \\
\hline $\operatorname{mi} 310$ & II & 18.6 & 29 & 44 & 54 & $0.30(P>0.59)$ \\
\hline m429 & II & 73.2 & 12 & 34 & 35 & $2.94(P>0.09)$ \\
\hline nga168 & II & 73.8 & 75 & 172 & 44 & $2.81(P>0.09)$ \\
\hline athBIO2 & II & 76.1 & 77 & 178 & 43 & $3.24(P>0.07)$ \\
\hline nga249 & V & 23.7 & 23 & 55 & 41 & $1.79(P>0.18)$ \\
\hline nga76 & $\mathrm{V}$ & 68.4 & 22 & 80 & 28 & $16.20(P<0.001)$ \\
\hline SO191 & V & 79.9 & 29 & 172 & 17 & $75.6(P<0.001)$ \\
\hline spl2 & V & 91.6 & 13 & 168 & 8 & $120.0(P<0.001)$ \\
\hline nga129 & V & 105.4 & 21 & 168 & 13 & $94.5(P<0.001)$ \\
\hline
\end{tabular}

${ }^{a}$ Only markers on chromosomes 2 and 5 are shown. No linkage was observed with the following markers: nga63 and nga128 on chromosome 1; nga162, glabrous 1, and PUR5 on chromosome 3; nga8 and nga11 on chromosome 4.

${ }^{\mathrm{b}} \mathrm{cM}=$ centimorgans; map positions are from the Dean-Lister Columbia $\times$ Landsberg recombinant inbred population.

${ }^{c} \chi^{2}$ and probability $(P)$ values are given for a 1:2 ratio of recombinant versus total chromosomes (as expected for loci unlinked to developmentally regulated resistance) 
that ARR is mechanistically distinct from SAR, ISR, and basal resistance (Kus et al. 2002). Flowering tobacco plants also display enhanced resistance to several pathogens that are highly virulent at earlier developmental stages, including Tobacco mosaic virus and the oomycete pathogens Phytophthora parasitica (black shank) and Peronospora tabacina (blue mold) (Hugot et al. 1999; Reuveni et al. 1986; Wyatt et al. 1991; Yalpani et al. 1993). Gene expression studies in tobacco have revealed that defense-associated genes are globally upregulated after the transition to flowering (Fraser 1981; Hugot et al. 1999, 2004; Lotan et al. 1989; Uknes et al. 1993; Yalpani et al. 1993). This upregulation occurs independently of pathogen attack and is triggered by endogenous developmental signals that include SA. Interestingly, tobacco resistance to blue mold is activated before the transition to reproductive growth in lateflowering tobacco lines, and the authors of this study speculate that resistance could be triggered by the onset of senescence (Wyatt and Kuc 1992). This idea is supported by reports that defense-associated genes can be activated during senescence (Morris et al. 2000; Quirino et al. 1999). Panter and Jones (2002) have postulated distinct "flowering-induced" and "senescence-induced" pathways for developmentally regulated resistance.

The developmentally regulated, $R P P 31$-dependent resistance characterized in this study differs significantly from the examples cited above. Most obviously, RPP31-dependent resistance is activated before the transition to flowering or the onset of senescence. The striking contrast in the responses of true leaves compared with those of cotyledons suggests that a component of RPP31-dependent resistance is activated upon the developmental phase change from postembryonic to juvenile growth (Kerstetter and Poethig 1998). Additionally, RPP31 resistance is race-specific. This contrasts with the broad-spectrum resistance against viruses and multiple oomycete species in flowering tobacco. Arabidopsis ARR to P. syringae is effective against two strains and may be similarly broad spectrum (Kus et al. 2002). RPP31 resistance is further distinguished from Arabidopsis ARR against $P$. syringae in terms of its genetic requirements. Both types of resistance are suppressed by NahG and, therefore, may be SA-dependent. In contrast, ARR against $P$. syringae is functional in the nprl-1 mutant background, while $R P P 31$ resistance is partially suppressed by nprl-1 (Kus et al. 2002). Finally, ARR against $P$. syringae is functional in the Ws- 0 background, while RPP31 resistance is not.

Considering the race specificity of $R P P 31$ resistance as well as its correlation with an oxidative burst and cell death and its genetic dependence upon known components of $R$ protein signal transduction, it seems likely that RPP31-dependent resistance is underpinned by a gene-for-gene interaction. In principle, the naturally variable $R P P 31$ locus could encode either an $\mathrm{R}$ protein, another type of resistance signaling component, or a "guardee." Although we cannot rule out the latter two possibilities until RPP31 is cloned, it seems likely that RPP31 encodes an $\mathrm{R}$ protein, because every naturally variable $R P P$ gene cloned to date encodes a NBS-LRR or receptor-like protein (RLP) (Slusarenko and Schlaich 2003; Tor et al. 2004). To our knowledge, no examples of intraspecific polymorphism among resistance signaling components or guardees has been described in Arabidopsis, with the possible exception of the ISRI locus that has been postulated as a regulator of ISR (Pieterse et al. 2003). Like RPP31, ISRI is functional in Col and nonfunctional in Ws, but ISR 1 has been mapped to chromosome 3 and, therefore, is not allelic with RPP31 (Ton et al. 2001). The $R P P 31$ mapping interval on chromosome 5 encompasses four genetically defined resistance genes: RPP8, RPS4, TTR1, and RRS1 (Deslandes et al. 2002; Gassmann et al. 1999; Lee et al. 1996; McDowell et al. 1998). Our analysis of knockouts from the Salk collection demonstrated that RPP8-Col is unnecessary for adult resistance. The allelic relationships of RPP31, RPS4, $T T R 1$, and $R R S 1$ remain to be clarified. The RPP31 mapping interval encompasses a large number of uncharacterized NBSLRR genes that represent potential candidates for RPP31 (Meyers et al. 2003; Tor et al. 2004).

Several cases of developmentally regulated, gene-for-gene resistance have been documented previously. For example, the tomato gene $C f-9 B$ provides resistance to the leaf mold pathogen Cladosporium fulvum and tomato $\mathrm{Mi}-1.2$ provides resistance to aphids and whiteflies (Goggin et al. 2004; Panter et al. 2002; Parniske et al. 1997). Both of these resistances are activated after the transition to flowering. The rice gene $X a-21$, for resistance against sheath blight (Xanthomonas oryzae), is nonfunctional in seedlings but becomes progressively more efficient from 21 days onward (Century et al. 1999). Finally, Arabidopsis resistance genes in the RPPl cluster are functional in leaves but not roots (Hermanns et al. 2003).

One obvious hypothesis to explain developmentally regulated, gene-for-gene resistance is that expression of the $R$ gene itself is developmentally regulated. Interestingly, expression studies of the genes cited above do not support this hypothesis. Transcripts from $X a-21, C f-9 B, M i-1.2$, and $R P P l$ were detected at approximately equivalent levels in resistant and susceptible tissues (Century et al. 1999; Goggin et al. 2004; Hermanns et al. 2003; Panter et al. 2002). The $C f-9 B$ promoter was shown to be functionally equivalent to the promoter of the $C f-9$ gene, which confers resistance in seedlings as well as mature plants (Panter et al. 2002). Finally, a transgene fusion of the constitutive cauliflower mosaic virus $35 \mathrm{~S}$ promoter to the $M i-1.2$ coding sequence was highly expressed in seedlings but did not confer resistance (Goggin et al. 2004). These results indicate that differential regulation of $R$ gene transcription is not a major mechanism underlying developmentally regulated resistance. However, none of the studies described above examined $\mathrm{R}$ protein abundance. Thus, it is possible that the $R$ gene products are regulated by translational or posttranslational mechanisms.

The studies described in the previous paragraph speak to the question of why RPP31-dependent resistance is active in true leaves but not in seedlings. The simplest explanation is that $R P P 31$ encodes a resistance gene that is expressed in true leaves but not seedlings. Although the precedents discussed above argue against this hypothesis, it cannot be ruled out at present. It is also possible that a regulator of resistance, acting upstream or downstream of an $\mathrm{R}$ protein, is nonfunctional or is not expressed in seedlings. Finally, the developmental component of RPP31 resistance could be provided by a differentially expressed guardee, a plant protein that is targeted by an Emco5 virulence factor and is guarded by RPP31 (Panter and Jones 2002; Panter et al. 2002).

Another intriguing aspect of RPP31 is its genetic recessivity. The majority of $R$ genes that have been cloned are genetically dominant, and little is known about molecular differences distinguishing dominant and recessive resistance genes (Chu et al. 2004; Li et al. 2001). A small number of recessive resistance genes have been cloned, and most do not encode NBSLRR or RLP proteins. The best-studied recessive resistance gene is mlo from barley, which encodes a seven-transmembrane domain protein (Büschges et al. 1997). Loss-of-function mlo alleles confer broad-spectrum, durable resistance to powdery mildew. The exact function of Mlo is unclear, but it is currently thought to function as a component of the defense machinery and as a compatibility target that the pathogen actively manipulates to facilitate colonization (Schulze-Lefert 2004). Other recessive resistance genes that have been recently cloned include $p v r 1 / p v r 2$ from pepper, $s b m 1$ from pea, and moll and mol 2 from lettuce, all of which function in resistance 
to different potyviruses (Gao et al. 2004; Kang et al. 2005; Nicaise et al. 2003; Ruffel et al. 2002). These genes encode isoforms of eukaryotic translation initiation factor $4 \mathrm{e}$, which likely functions as a host compatibility factor to facilitate viral replication and movement. The rice Xa5 and the Arabidopsis RRS1 genes provide recessive resistance against Xanthomonas oryzae and Ralstonia solanacearum, respectively. Xa5 encodes the gamma subunit of transcription factor IIA (Iyer and McCouch 2004). The role of this protein in resistance is currently unclear; however, the cognate Avr protein is localized to the nucleus, suggesting that $X a 5$ may also function in compatibility. RRS1 is the only cloned recessive resistance gene with molecular similarity to dominant $R$ genes. $R R S 1$ encodes a Toll and interleukin 1 receptor (TIR)-NBS-LRR protein with an atypical WRKY DNA-binding domain at the C-terminus (Deslandes et al. 2002). RRS1 appears to associate directly with the cognate avirulence protein in the nucleus. The molecular basis of RRS1 recessivity is currently unknown and somewhat enigmatic, because $R R S 1$ transgenes are genetically dominant when expressed in an rrsl background (Deslandes et al. 2002, 2003).

One explanation for $R P P 31$ recessivity, from the precedents discussed above, is that $R P P 31$ encodes a naturally variable compatibility factor that is nonfunctional in the Ws-0 background. However, as discussed above, we favor the hypothesis that RPP31 encodes an NBS-LRR resistance protein. Perhaps $R P P 31$ encodes a "weak" $\mathrm{R}$ protein with low affinity for an interacting protein, such that two doses are necessary to activate resistance. Our gene-dosage experiments indicate that resistance is dose-dependent because triploid $\mathrm{Col} / \mathrm{Col} / \mathrm{Ws}-0$ hybrids were noticeably more resistant than diploid Col-0/Ws0 hybrids. However, the triploid hybrids consistently permitted more pathogen growth and reproduction than did diploid or tetraploid Col. This phenotype is inconsistent with a hypothesis of simple haploinsufficiency, suggesting that a Ws-0 allele exerts a negative, incompletely dominant effect on Col-0 resistance. This and other aspects of RPP31-dependent resistance would likely be clarified by map-based cloning of $R P P 31$.

In closing, it is relevant to note that genes for developmentally regulated resistance to $H$. parasitica have been identified in broccoli and cabbage cultivars (Brassica oleracea) (Coelho and Monteiro 2003; Dickson and Petzoldt 1993; Wang et al. 2000). Like RPP31, these genes provide resistance in true leaves but not in cotyledons. Cultivated Brassicas like broccoli and cauliflower are particularly susceptible to downy mildew disease at the seedling stage, because they are grown in propagation tray systems under high humidity that promotes disease development (Brophy and Laing 1992). Thus, it would be of potential agronomic utility as well as of fundamental interest to compare the mechanisms underlying developmental resistance to downy mildew disease in the Brassica and Arabidopsis genera.

\section{MATERIALS AND METHODS}

\section{Plant and pathogen lines, growth conditions, and pathogen inoculations.}

rpm1-3 contains a loss-of-function allele of the bacterial resistance gene RPM1 in the Col-5 (glabrous 1) background (Boyes et al. 1998; Grant et al. 1995). CS3432 and CS3151 are tetraploid lines in the Columbia background (Greenberg 2000). Adult-resistance phenotypes in rpm1-3, CS3432, and CS3151 lines are indistinguishable from wild-type Col-0 (data not shown). H. parasitica isolates Emco5 and Ahco2 were previously described (Holub and Beynon 1996; McDowell et al. 1998) and were propagated on Ws-0 or Col-0 plants, respectively, at 7-day intervals.
Plants for pathogen-challenge experiments were grown at $23^{\circ} \mathrm{C}$ under 8 or 10 -h day length, with light intensities of approximately $200 \mu \mathrm{E}$ in Sunshine mix number one (Sun Gro Horticulture, Bellevue, WA, U.S.A.). Plants for adult-resistance assays were germinated in 4-in pots and were grown for 2 weeks, after which they were transplanted to $10 \times 17$-in flats in matrices of 10 columns by 5 rows. Inoculations were performed 7, 14, or 21 days later, by spraying plants with a suspension of $5 \times 10^{4}$ spores $/ \mathrm{ml}$ in distilled water to the point of imminent run-off. Flats were covered with a plastic dome for 12 to $18 \mathrm{~h}$, were uncovered for 3 days, and then, were covered again until they were scored at 7 dai. Comparisons of agematched transplanted and nontransplanted plants were performed to confirm that resistance and susceptibility phenotypes were not affected by transplantation. Senescence was never observed in 3- and 4-week old plants and occurred only rarely in 5-week old plants. Staining with trypan blue was performed as described (McDowell et al. 1998), and images were captured on a Zeiss Axioscop2 compound microscope with a Spot digital camera. Images of sporulating plants were captured on a Zeiss SV11 stereomicroscope using a JVC digital camera and Automontage imaging software (Syncroscopy, Inc., Frederick, MD, U.S.A.).

\section{Genetic mapping.}

Crosses were performed by manual emasculation and pollination and were verified by visual or molecular markers. F2 plants were inoculated and scored as described above. Plants that displayed a Col-like adult-resistance phenotype were immediately inoculated a second time with Emco5 and were scored one week later to rule out the possibility that the resistance phenotype was due to a low dose of inoculum during the initial screen. DNA was isolated from one leaf of each plant that passed both screenings, and genetic mapping was conducted with CAPS and SSLP markers. Molecular markers were amplified by PCR and were assayed as described by The Arabidopsis Information Resource, except for SPL2. Primers 5'GAAATTGATGGATTTGATTGC-3' and 5'-ATGCTATAACT GAACTATAGGC-3' amplified a $1.5-\mathrm{kb}$ band that is polymerphic after digestion with the Dde1 restriction enzyme.

\section{ACKNOWLEDGMENTS}

We thank members of the McDowell lab and B. Vinatzer for helpful comments on the manuscript. Tetraploid Col lines and Salk T-DNA insertion lines were provided by the Arabidopsis Biological Resource Center, Ohio State University, which is supported by the National Science Foundation. This research was supported by grants from the United States Department of Agriculture, National Research Initiative (98-024282 and 0235319 to J. M. McDowell and 99-35301 and 02-35301 to J. L. Dangl) and by Hatch grant funding to J. M. McDowell.

\section{LITERATURE CITED}

Aarts, N., Metz, M., Holub, E., Staskawicz, B. J., Daniels, M. J., and Parker, J. E. 1998. Different requirements for EDS1 and NDR1 by disease resistance genes define at least two $R$ gene-mediated pathways in Arabidopsis. Proc. Natl. Acad. Sci. U.S.A. 95:10306-10311.

Alonso, J. M., Stepanova, A. N., Leisse, T. J., Kim, C. J., Chen, H., Shinn, P., Stevenson, D. K., Zimmerman, J., Barajas, P., Cheuk, R., Gadrinab, C., Heller, C., Jeske, A., Koesema, E., Meyers, C. C., Parker, H., Prednis, L., Ansari, Y., Choy, N., Deen, H., Geralt, M., Hazari, N., Hom, E., Karnes, M., Mulholland, C., Ndubaku, R., Schmidt, I., Guzman, P., Aguilar-Henonin, L., Schmid, M., Weigel, D., Carter, D. E., Marchand, T., Risseeuw, E., Brogden, D., Zeko, A., Crosby, W. L., Berry, C. C., and Ecker, J. R. 2003. Genome-wide insertional mutagenesis of Arabidopsis thaliana. Science 301:653-657.

Bieri, S., Mauch, S., Shen, Q. H., Peart, J., Devoto, A., Casais, C., Ceron, F., Schulze, S., Steinbiss, H. H., Shirasu, K., and Schulze-Lefert, P. 2004. RAR1 positively controls steady state levels of barley MLA resistance proteins and enables sufficient MLA6 accumulation for effective 
resistance. Plant Cell 16:3480-3495.

Bowling, S. A., Guo, A., Cao, H., Gordon, A. S., Klessig, D. F., and Dong, X. 1994. A mutation in Arabidopsis that leads to constitutive expression of systemic acquired resistance. Plant Cell 6:1845-1857.

Boyes, D.C., Nam, J., and Dangl, J. L. 1998. The Arabidopsis thaliana RPM1 disease resistance gene product is a peripheral plasma membrane protein that is degraded coincident with the hypersensitive response. Proc. Natl. Acad. Sci. U.S.A. 95:15849-15854.

Brophy, T. F., and Laing, M. D. 1992. Screening of fungicides for the control of downy mildew on container-grown cabbage seedlings. Crop Prot. 11:160-164.

Büschges, R., Hollricher, K., Panstruga, R., Simons, G., Wolter, M., Frijters, A., van Daelen, R., van der Lee, T., Diergaarde, P., Groenendijk, J., Töpsch, S., Vos, P., Salamini, F., and Schulze-Lefert, P. 1997. The barley Mlo gene: A novel control element of plant pathogen resistance. Cell 88:695-706.

Cameron, R. K., and Zaton, K. 2005. Intercellular salicylic acid accumulation is important for age-related resistance in Arabidopsis to Pseudomonas syringae. Physiol. Mol. Plant Pathol. 65:197-209.

Cao, H., Glazebrook, J., Clark, J. D., Volko, S., and Dong, X. 1997. The Arabidopsis NPR1 gene that controls systemic acquired resistance encodes a novel protein containing ankyrin repeats. Cell 88:57-64.

Century, K. S., Shapiro, A. D., Repetti, P. P., Dahlbeck, D., Holub, E., and Staskawicz, B. J. 1997. NDR1, a pathogen-induced component required for Arabidopsis disease resistance. Science 278:1963-1965.

Century, K. S., Lagman, R. A., Adkisson, M., Morlan, J., Tobias, R., Schwartz, K., Smith, A., Love, J., Ronald, P. C., and Whalen, M. C. 1999. Short communication: Developmental control of Xa21-mediated disease resistance in rice. Plant J 20:231-236.

Chang, J. H., Goel, A. K., Grant, S. R., and Dangl, J. L. 2004. Wake of the flood: Ascribing functions to the wave of type III effector proteins of phytopathogenic bacteria. Curr. Opin. Microbiol. 7:11-18.

Chu, Z., Ouyang, Y., Zhang, J., Yang, H., and Wang, S. 2004. Genomewide analysis of defense-responsive genes in bacterial blight resistance of rice mediated by the recessive $\mathrm{R}$ gene xal3. Mol. Genet. Genom. 271:111-120.

Clark, J., and Spencer-Phillips, P. 2000. Downy Mildews. Pages 117-129 in: Encyclopedia of Microbiology. Vol. 2. Academic Press, Inc.

Clarke, J. D., Liu, Y., Klessig, D. F., and Dong, X. 1998. Uncoupling PR gene expression from NPR1 and bacterial resistance: Characterization of the dominant Arabidopsis cpr6-1 mutant. Plant Cell 10:557-569.

Coelho, P. S., and Monteiro, A. A. 2003. Expression of resistance to downy mildew at cotyledon and adult plant stages in Brassica oleracea L. Euphytica 133:279-284.

Coppinger, P., Repetti, P. P., Day, B., Dahlbeck, D., Mehlert, A., and Staskawicz, B. J. 2004. Overexpression of the plasma membrane-localized NDR1 protein results in enhanced bacterial disease resistance in Arabidopsis thaliana. Plant J 40:225-237.

Crute, I. R., and Pink, D. A. 1996. Genetics and utilization of pathogen resistance in plants. Plant Cell 8:1747-1755.

Dangl, J. L., and Jones, J. D. 2001. Plant pathogens and integrated defence responses to infection. Nature 411:826-833.

Delaney, T., Uknes, S., Vernooij, B., Friedrich, L., Weymann, K., Negrotto, D., Gaffney, T., Gut-Rella, M., Kessman, H., Ward, E., and Ryals, J. 1994. A central role of salicylic acid in plant disease resistance. Science 266:1247-1250

Deslandes, L., Olivier, J., Theulieres, F., Hirsch, J., Feng, D. X., BittnerEddy, P., Beynon, J., and Marco, Y. 2002. Resistance to Ralstonia solanacearum in Arabidopsis thaliana is conferred by the recessive RRS1$R$ gene, a member of a novel family of resistance genes. Proc. Natl. Acad. Sci. U.S.A. 99:2404-2409.

Deslandes, L., Olivier, J., Peeters, N., Feng, D. X., Khounlotham, M., Boucher, C., Somssich, I., Genin, S., and Marco, Y. 2003. Physical interaction between RRS1-R, a protein conferring resistance to bacterial wilt, and PopP2, a type III effector targeted to the plant nucleus. Proc. Natl. Acad. Sci. U.S.A. 100:8024-8029.

Dickson, M. H., and Petzoldt, R. 1993. Plant-age and isolate source affect expression of downy mildew resistance in broccoli. Hortscience 28:730-731.

Durrant, W. E., and Dong, X. 2004. Systemic acquired resistance. Ann. Rev. Phytopathol. 42:185-209.

Flor, H. H. 1955. Host-parasite interactions in flax-its genetics and other implications. Phytopathology 45:680-685.

Fraser, R. S. S. 1981. Evidence for the occurrence of the pathogenesisrelated proteins in leaves of healthy tobacco plants during flowering. Physiol. Plant Pathol. 19:69-76.

Gao, Z. H., Johansen, E., Eyers, S., Thomas, C. L., Noel Ellis, T. H., and Maule, A. J. 2004. The potyvirus recessive resistance gene, sbm 1, identifies a novel role for translation initiation factor eIF4E in cell-to-cell trafficking. Plant J. 40:376-385.
Gassmann, W., Hinsch, M. E., and Staskawicz, B. J. 1999. The Arabidopsis RPS4 bacterial-resistance gene is a member of the TIR-NBS-LRR family of disease-resistance genes. Plant J. 20:265-277.

Glazebrook, J., Rogers, E. E., and Ausubel, F. M. 1997. Use of Arabidopsis for genetic dissection of plant defense responses. Annu. Rev. Genet 31:547-569.

Goggin, F. L., Shah, G., Williamson, V. M., and Ullman, D. E. 2004. Developmental regulation of $M i$-mediated aphid resistance is independent of Mi-1.2 transcript levels. Mol. Plant-Microbe Interact. 17:532-536.

Grant, M. R., Godiard, L., Straube, E., Ashfield, T., Lewald, J., Sattler, A., Innes, R. W., and Dangl, J. L. 1995. Structure of the Arabidopsis RPM1 gene enabling dual specificity disease resistance. Science 269:843-846.

Greenberg, J. T. 2000. Positive and negative regulation of salicylic aciddependent cell death and pathogen resistance in Arabidopsis lsd6 and ssi1 mutants. Mol. Plant-Microbe Interact. 13:877-881.

Griffey, C. A., Das, M. K., and Stromberg, E. L. 1993. Effectiveness of adult-plant resistance in reducing grain-yield loss to powdery mildew in winter-wheat. Plant Dis. 77:618-622.

Hammond-Kosack, K. E., and Jones, J. D. G. 1996. Inducible plant defense mechanisms and resistance gene function. Plant Cell 8:1773-1791.

Hammond-Kosack, K. E., and Parker, J. E. 2003. Deciphering plant-pathogen communication: Fresh perspectives for molecular resistance breeding. Curr. Opin. Biotechnol. 14:177-193.

Hermanns, M., Slusarenko, A. J., and Schlaich, N. L. 2003. Organ-specificity in a plant disease is determined independently of $R$ gene signaling. Mol. Plant-Microbe Interact. 16:752-759.

Holub, E. B. 1997. Organisation of resistance genes in Arabidopsis. Pages 526 in: The Gene-for-Gene Relationship in Plant-Parasite Interactions. I. R Crute, E. B. Holub, and J. J. Burdon, eds. CAB International New York,

Holub, E. B. 2001. The arms race is ancient history in Arabidopsis, the wildflower. Nat. Rev. Genet. 2:516-527.

Holub, E. B., and Beynon, J. L. 1996. Symbiology of mouse ear cress (Arabidopsis thaliana) and oomycetes. Adv. Bot. Res. 24:228-273.

Holub, E., Crute, I., Brose, E., and Beynon, J. 1993. Identification and mapping of loci in Arabidopsis for resistance to downy mildew and white blister. Pages 21-35 in: Arabidopsis thaliana as a Model for Plant-Pathogen Interactions. K. Davis and R. Hammerschmidt, eds. American Phytopathological Society Press, St. Paul, MN, U.S.A.

Holub, E. B., Beynon, J. L., and Crute, I. R. 1994. Phenotypic and genotypic characterization of interactions between isolates of Peronospora parasitica and accessions of Arabidopsis thaliana. Mol. Plant-Microbe Interact. 7:223-239.

Hugot, K., Aime, S., Conrod, S., Poupet, A., and Galiana, E. 1999. Developmental regulated mechanisms affect the ability of a fungal pathogen to infect and colonize tobacco leaves. Plant J. 20:163-170.

Hugot, K., Riviere, M. P., Moreilhon, C., Dayem, M. A., Cozzitorto, J., Arbiol, G., Barbry, P., Weiss, C., and Galiana, E. 2004. Coordinated regulation of genes for secretion in tobacco at late developmental stages: Association with resistance against oomycetes. Plant Physiol. 134:858-870.

Iyer, A. S., and McCouch, S. R. 2004. The rice bacterial blight resistance gene $x a 5$ encodes a novel form of disease resistance. Mol. PlantMicrobe Interact. 17:1348-1354.

Jirage, D., Tootle, T. L., Reuber, T. L., Frost, L. N., Feys, B. J., Parker, J. E., Ausubel, F. M., and Glazebrook, J. 1999. Arabidopsis thaliana $P A D 4$ encodes a lipase-like gene that is important for salicylic acid signaling. Proc. Natl. Acad. Sci. U.S.A. 96:13583-13588.

Jones, D. A., and Jones, J. D. G. 1996. The roles of leucine rich repeats in plant defences. Adv. Bot. Res. Adv. Plant Pathol. 24:90-167.

Kang, B.-C., Yeam, I., Frantz, J., Murphy, J., and Jahn, M. 2005. The $p v r I$ locus in Capsicum encodes a translation initiation factor eIF4E that interacts with Tobacco etch virus VPg. Plant J. 42:392-405.

Katagiri, F. 2004. A global view of defense gene expression regulation-A highly interconnected signaling network. Curr. Opin. Plant Biol. 7:506511.

Kerstetter, R. A., and Poethig, R. S. 1998. The specification of leaf identity during shoot development. Ann. Rev. Cell Dev. Biol. 14:373-398.

Kolmer, J. A. 1996. Genetics of resistance to wheat leaf rust. Ann. Rev. Phytopathol. 34:435-455

Korves, T. M., and Bergelson, J. 2003. A developmental response to pathogen infection in Arabidopsis. Plant Physiol. 133:339-347.

Kus, J. V., Zaton, K., Sarkar, R., and Cameron, R. K. 2002. Age-related resistance in Arabidopsis is a developmentally regulated defense response to Pseudomonas syringae. Plant Cell 14:479-490.

Lee, J. M., Hartman, G. L., Domier, L. L., and Bent, A. F. 1996. Identification and map location of TTR1, a single locus in Arabidopsis thaliana that confers tolerance to tobacco ringspot nepovirus. Mol. PlantMicrobe Interact. 9:729-735.

Li, Z. K., Sanchez, A., Angeles, E., Singh, S., Domingo, J., Huang, N., and Khush, G. S. 2001. Are the dominant and recessive plant disease resis- 
tance genes similar? A case study of rice $R$ genes and Xanthomonas oryzae pv. oryzae races. Genetics 159:757-765.

Liu, S. X., Griffey, C. A., and Maroof, M. A. S. 2001. Identification of molecular markers associated with adult plant resistance to powdery mildew in common wheat cultivar Massey. Crop Sci. 41:1268-1275.

Lotan, T., Ori, N., and Fluhr, R. 1989. Pathogenesis-related proteins are developmentally regulated in tobacco flowers. Plant Cell 1:881-887.

McDowell, J. M., Dhandaydham, M., Long, T. A., Aarts, M. G., Goff, S., Holub, E. B., and Dangl, J. L. 1998. Intragenic recombination and diversifying selection contribute to the evolution of downy mildew resistance at the RPP8 locus of Arabidopsis. Plant Cell 10:1861-1874.

McDowell, J. M., Cuzick, A., Can, C., Beynon, J., Dangl, J. L., and Holub, E. B. 2000. Downy mildew (Peronospora parasitica) resistance genes in Arabidopsis vary in functional requirements for NDR1, EDS1, NPR1 and salicylic acid accumulation. Plant J. 22:523-529.

McDowell, J. M., and Dangl, J. L. 2000. Signal transduction in the plant immune response. Trends Biochem. Sci. 25:79-82.

Meyers, B. C., Kozik, A., Griego, A., Kuang, H. H., and Michelmore, R. W. 2003. Genome-wide analysis of NBS-LRR-encoding genes in Arabidopsis. Plant Cell 15:809-834.

Morris, K., Mackerness, S. A. H., Page, T., John, C. F., Murphy, A. M., Carr, J. P., and Buchanan-Wollaston, V. 2000. Salicylic acid has a role in regulating gene expression during leaf senescence. Plant J. 23:677685

Nicaise, V., German-Retana, S., Sanjuan, R., Dubrana, M. P., Mazier, M., Maisonneuve, B., Candresse, T., Caranta, C., and LeGall, O. 2003. The eukaryotic translation initiation factor $4 \mathrm{E}$ controls lettuce susceptibility to the potyvirus Lettuce mosaic virus. Plant Physiol. 132:1272-1282.

Osbourn, A. E. 1996. Preformed antimicrobial compounds and plant defense against fungal attack. Plant Cell 8:1821-1831.

Panter, S. N., and Jones, D. A. 2002. Age-related resistance to plant pathogens. Adv. Bot. Res. 38:251-280.

Panter, S. N., Hammond-Kosack, K. E., Harrison, K., Jones, J. D. G., and Jones, D. A. 2002. Developmental control of promoter activity is not responsible for mature onset of $C f-9 B$-mediated resistance to leaf mold in tomato. Mol. Plant-Microbe Interact. 15:1099-1107.

Parker, J. E., Holub, E. B., Frost, L. N., Falk, A., Gunn, N. D., and Daniels, M. J. 1996. Characterization of eds1, a mutation in Arabidopsis suppressing resistance to Peronospora parasitica specified by several different RPP genes. Plant Cell 8:2033-2046.

Parniske, M., Hammond-Kosack, K. E., Golstein, C., Thomas, C. M., Jones, D. A., Harrison, K., Wulff, B. B. H., and Jones, J. D. G. 1997. Novel disease resistance specificities result from sequence exchange between tandemly repeated genes at the $C f-4 / 9$ locus of tomato. Cell 91:821-832.

Pieterse, C. M. J., Van Pelt, J. A., Verhagen, B. W. M., Ton, J., Van Wees, S. C. M., Leon-Kloosterziel, K. M., and Van Loon, L. C. 2003. Induced systemic resistance by plant growth-promoting rhizobacteria. Symbiosis 35:39-54.

Quirino, B. F., and Bent, A. F. 2003. Deciphering host resistance and pathogen virulence: The Arabidopsis/Pseudomonas interaction as a model. Mol. Plant Pathol. 4:517-530.

Quirino, B. F., Normanly, J., and Amasino, R. M. 1999. Diverse range of gene activity during Arabidopsis thaliana leaf senescence includes pathogen-independent induction of defense-related genes. Plant Mol. Biol. 40:267-278.

Reuveni, M., Tuzun, S., Cole, J. S., Siegel, M. R., and Kuc, J. 1986. The effects of plant-age and leaf position on the susceptibility of tobacco to blue mold caused by Peronospora tabacina. Phytopathology 76:455458

Ruffel, S., Dussault, M. H., Palloix, A., Moury, B., Bendahmane, A., Robaglia, C., and Caranta, C. 2002. A natural recessive resistance gene against Potato virus $Y$ in pepper corresponds to the eukaryotic initiation factor 4E (eIF4E). Plant J. 32:1067-1075.

Schulze-Lefert, P. 2004. Knocking on heaven's wall: Pathogenesis of and resistance to biotrophic fungi at the cell wall. Curr. Opin. Plant Biol. 7:377-383.

Shapiro, A. D., and Zhang, C. 2001. The role of NDR1 in avirulence genedirected signaling and control of programmed cell death in Arabidopsis. Plant Physiol. 127:1089-1101.
Shirasu, K., and Schulze-Lefert, P. 2003. Complex formation, promiscuity and multi-functionality: Protein interactions in disease-resistance pathways. Trends Plant Sci. 8:252-258.

Slusarenko, A., and Schlaich, N. 2003. Downy mildew of Arabidopsis thaliana caused by Hyaloperonospora parasitica (formerly Peronospora parasitica). Mol. Plant Pathol. 4:159-170.

Staswick, P. E., Serban, B., Rowe, M., Tiryaki, I., Maldonado, M. T., Maldonado, M. C., and Suza, W. 2005. Characterization of an Arabidopsis enzyme family that conjugates amino acids to indole-3-acetic acid. Plant Cell 17:616-627.

Sunderwirth, S. D., and Roelfs, A. P. 1980. Greenhouse evaluation of the adult-plant resistance of $\mathrm{Sr} 2$ to wheat-stem rust. Phytopathology 70:634-637.

Tameling, W. I. L., Elzinga, S. D. J., Darmin, P. S., Vossen, J. H., Takken, F. L. W., Haring, M. A., and Cornelissen, B. J. C. 2002. The tomato $R$ gene products I-2 and Mi-1 are functional ATP binding proteins with ATPase activity. Plant Cell 14:2929-2939.

Tao, Y., Xie, Z., Chen, W., Glazebrook, J., Chang, H.-S., Han, B., Zhua, T. Zou, G., and Katagiri, F. 2003. Quantitative nature of Arabidopsis responses during compatible and incompatible interactions with the bacterial pathogen Pseudomonas syringae. Plant Cell 15:317-330.

Telfer, A., Bollman, K. M., and Poethig, R. S. 1997. Phase change and the regulation of trichome distribution in Arabidopsis thaliana. Development 124:645-654.

Ton, J., Davison, S., Van Loon, L. C., and Pieterse, C. M. J. 2001. Heritability of rhizobacteria-mediated induced systemic resistance and basal resistance in arabidopsis. Eur. J. Plant Pathol. 107:63-68.

Tor, M., Brown, D., Cooper, A., Woods-Tor, A., Sjolander, K., Jones, J. D. G., and Holub, E. B. 2004. Arabidopsis downy mildew resistance gene $R P P 27$ encodes a receptor-like protein similar to CLAVATA2 and tomato Cf-9. Plant Physiol. 135:1100-1112.

Tornero, P., Merritt, P., Sadanandom, A., Shirasu, K., Innes, R. W., and Dangl, J. L. 2002. RAR1 and NDR1 contribute quantitatively to disease resistance in Arabidopsis, and their relative contributions are dependent on the $R$ gene assayed. Plant Cell 14:1005-1015.

Torres, M. A., Dangl, J. L., and Jones, J. D. 2002. Arabidopsis gp91phox homologues AtrbohD and AtrbohF are required for accumulation of reactive oxygen intermediates in the plant defense response. Proc. Natl. Acad. Sci. U.S.A. 99:517-522.

Uknes, S., Dincher, S., Friedrich, L., Negrotto, D., Williams, S., Thompsontaylor, H., Potter, S., Ward, E., and Ryals, J. 1993. Regulation of pathogenesis-related protein-1a gene-expression in tobacco. Plant Cell 5:159-169.

Van der Biezen, E. A., and Jones, J. D. G. 1998. Plant disease-resistance proteins and the gene-for-gene concept. Trends Biochem. Sci. 12:454456.

Van't Slot, K. A. E., and Knogge, W. 2002. A dual role for microbial pathogen-derived effector proteins in plant disease and resistance. Crit. Rev. Plant Sci. 21:229-271.

Wang, M., Farnham, M. W., and Thomas, C. E. 2000. Phenotypic variation for downy mildew resistance among inbred broccoli. Hortscience 35:925-929.

Warren, R. F., Merritt, P. M., Holub, E., and Innes, R. W. 1999. Identification of three putative signal transduction genes involved in $R$ genespecified disease resistance in Arabidopsis. Genetics 152:401-412.

Wyatt, S. E., and Kuc, J. 1992. The effect of leaf age, flowering, and senescence on the resistance of tobacco to blue mold. Phytopathology 80:1000.

Wyatt, S. E., Pan, S. Q., and Kuc, J. 1991. Beta-1,3-Glucanase, chitinase, and peroxidase-activities in tobacco tissues resistant and susceptible to blue mold as related to flowering, age and sucker development. Physiol. Mol. Plant Pathol. 39:433-440.

Yalpani, N., Shulaev, V., and Raskin, I. 1993. Endogenous salicylic-acid levels correlate with accumulation of pathogenesis-related proteins and virus-resistance in tobacco. Phytopathology 83:702-708.

\section{AUTHOR-RECOMMENDED INTERNET RESOURCE}

The Arabidopsis Information Resource: www.arabidopsis.org 